\title{
Calculation of seepage surface and water flow on pumping wells for unconfined aquifers employing the network method

\author{
Encarnación Martínez-Moreno ${ }^{1}$, Iván Alhama ${ }^{1}$, Gonzalo García-Ros ${ }^{1}$ \\ ${ }^{1}$ Civil Engineering Department, Technical University of Cartagena \\ Paseo Alfonso XIII 52, Cartagena, Spain
} \\ encarni.martinez@upct.es; ivan.alhama@upct.es; gonzalo.garcia@upct.es
}

\begin{abstract}
Water scarcity has led to its extraction from underground reserves or aquifers, for which pumping wells are built. For this reason, the phenomenon has been mathematically (and then, computationally) modelled for either confined or unconfined aquifers. As former theoretical approaches to the problem, solution for groundwater flow in unconfined aquifers did not consider vertical flow and variables such as seepage surface were not studied. The aim of this work is to provide a methodology to estimate both parameters using a computational model based on the network method. This methodology consists on the analogy between electrical quantities (voltage and intensity) and geotechnical variables (water potential and flow). The results obtained with this tool are compared to those from scale models.
\end{abstract}

Keywords: Ground engineering, pumping wells, seepage surface, unconfined aquifers.

\section{Introduction}

Nowadays, due to the water scarcity around the globe [1], one of the aims of ground engineering is to obtain this resource from underground reserves, commonly known as aquifers. In order to abstract water from these reservoirs, pumping wells set (built) on ground surface.

Aquifers can be classified according to their permeability, which affects the ease of the wells to extract water from them, but the location of their water level is also important to consider regard. In this way, if water level is found over the upper limit of the aquifer, it is considered as confined, while when the level is located below this border, the aquifer is known as unconfined.

Traditionally, although the two classifications of aquifers behave differently when a pumping well is working, they have been mathematically studied under the same restriction: vertical flow is not considered. This condition is correct for confined aquifers, but not accurate enough for unconfined ones. Because of this, Dupuit's formulation [2], developed for unconfined aquifers, the position of groundwater level when pumping, is not correctly modelled; although it gives an accurate approximation for the water flow value.

Studying other structures with unconfined flow such as earth dams, the existence of a seepage surface appears [3]. This is an area where the water is running outside the porous structure and where pore pressure is atmospheric. This is the main reason why Dupuit's equation does not lead to correct results; it cannot consider the seepage surface above water level inside the well because only radial (horizontal) flow is modelled.

Employing the network method [4], which is based on the electrical analogy, a tool has been developed to calculate the water flow and the seepage surface in unconfined aquifers. This technique includes vertical flow, so the seepage surface can be obtained in an accurate manner. Network method is a technique applicable to the simulation of different physical problems, such as soil consolidation [5] and heat transfer [6]. The electrical analogy used in this methodology is the equivalence of groundwater head (h) with the electrical voltage (V), and the ground water flow (Q) with the electrical current (I), as the governing equation in both types of phenomena are akin. With this tool, once the scenario has been discretized, each cell is transformed into a circuit with four resistors whose resistance values vary according to the size of the cell and the permeability of the aquifer. The circuits are solved using Ngspice [7], obtaining in this way the voltage and current for all the elemental volumes. These are employed to calculate the values of water flow and seepage surface.

In this document, the values of water flow and seepage surface in unconfined aquifers are studied comparing the results of the developed tool and those obtained by Hall [8] and his scale model.

\section{Theoretical results: Hall's research}

In his article 'An investigation of steady flow toward a gravity well', Hall [8] built a scale model in order to compare those real results with the ones obtained by the relaxation method. This studied also included considering the 
capillary flow above the water level, so its value is higher than that calculated by Dupuit's formulation [2]. For this reason, the water flow value that later is compared to that of the developed model is Dupuit's.

Figure 1 shows the sketch and nomenclature of the study problem.

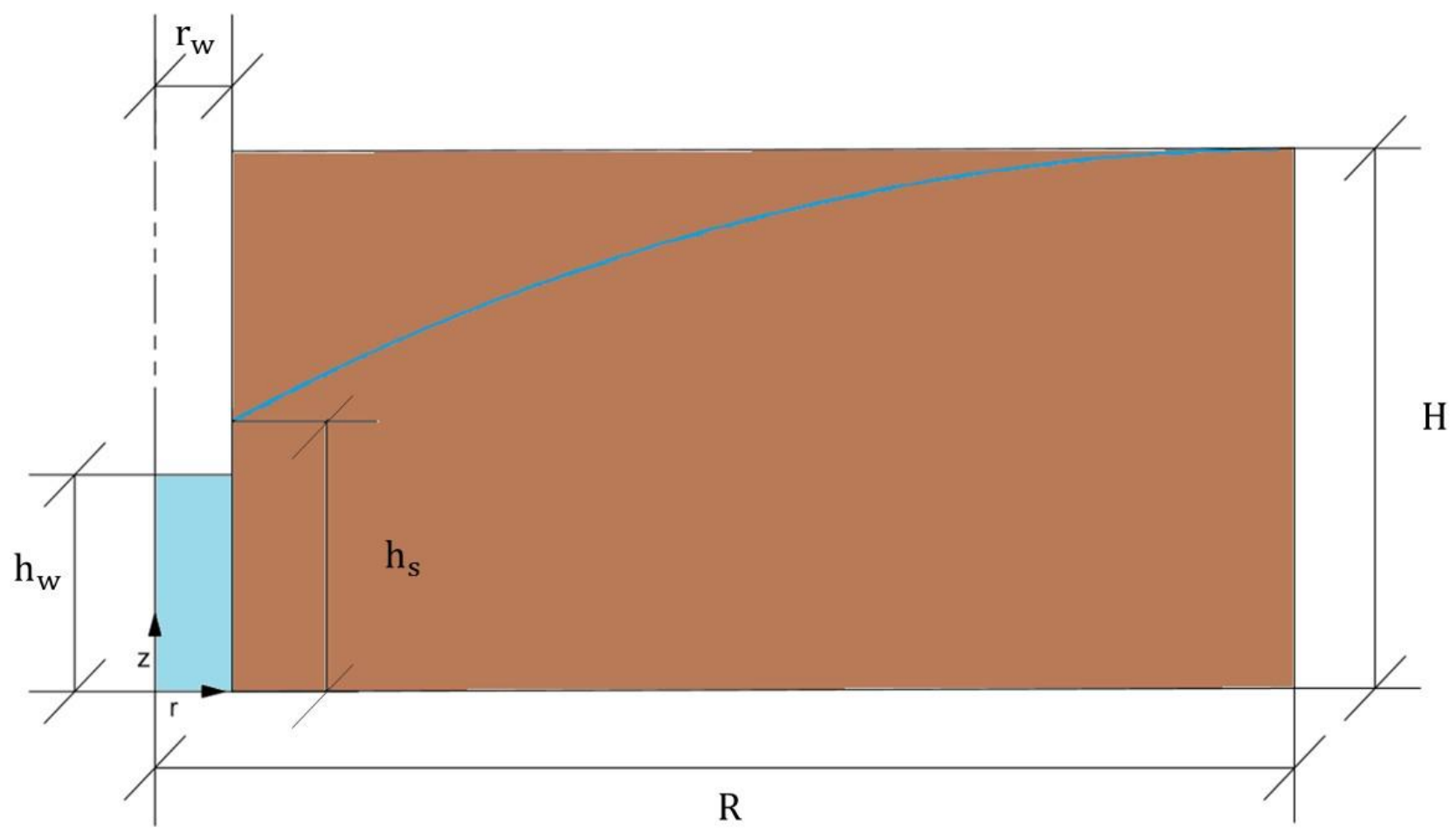

Fig. 1: Sketch and nomenclature of the problem.

In Hall's model, the aquifer radius $(\mathrm{R})$ was 1.976 meters, the well radius $\left(\mathrm{r}_{\mathrm{w}}\right)$ was 0.122 meters, and the aquifer water height $(\mathrm{H})$ was 1.22 meters. In addition, the hydraulic conductivity of the soil was $4.6 \mathrm{~mm} / \mathrm{s}$, this is $4.6 \cdot 10^{-3} \mathrm{~m} / \mathrm{s}$. Table 1 shows three of the tests that Hall carried out, where the variables presented are: water flow including the capillary flow ( $\mathrm{Q}_{\text {Hall }}$ ), water flow according to Dupuit's formula ( $\mathrm{QDup}_{\text {Dup }}$ and seepage surface $\left(h_{\text {seep,Hall }}\right)$. The water height $\left(h_{\text {well }}\right)$ in the well varies for each of the three tests. Both $\mathrm{Q}_{\text {Hall }}$ and $\mathrm{Q}_{\text {Dup }}$ are multiplied by $10^{-3}$.

Table 1: Data from Hall's experiments.

\begin{tabular}{|c|c|c|c|c|}
\hline Test & $\mathbf{h}_{\text {well }}(\mathbf{m})$ & $\mathbf{h}_{\text {seep, Hall }}(\mathbf{m})$ & $\mathbf{Q}_{\text {Hall }}\left(\mathbf{m}^{\mathbf{3}} / \mathbf{s}\right)$ & $\mathbf{Q}_{\text {Dup }}\left(\mathbf{m}^{\mathbf{3}} \mathbf{s}\right)$ \\
\hline A-2 & 0.912 & 1.043 & 3.86 & 3.41 \\
\hline A-6 & 0.304 & 0.848 & 8.28 & 7.25 \\
\hline A-8 & 0.000 & 0.833 & 8.78 & 7.73 \\
\hline
\end{tabular}

As commented before, the water flow values measured by Hall was higher than the values obtained with Dupuit's formulation. This is due to the consideration of the flow coming from the capillary zone, which is not modelled either by Dupuit's formulation or the developed code.

\section{Network method solutions}

As explained previously in this document, to study the problem of flow in unconfined aquifers due to pumping well with this technique, the first step is to divide the scenario in cells, which are transformed into circuits with two horizontal resistors and two vertical ones. The resistance values of these resistors depend on the size of the cell and the hydraulic conductivity of the porous medium. In addition, the borders of the scenario (boundary conditions) must be translated into electrical devices: constant water potential borders are modelled as 
batteries whose value is the same as the water height; and impervious borders are simulated with resistors of high resistance values.

When each cell is translated into the corresponding circuit, they are implemented in Ngspice, and this program provides the voltage and current values employed for the calculation of the water flow and seepage surface variables.

Table 2 shows the values of water flow $\left(\mathrm{Q}_{\text {exp }}\right)$ and seepage surface $\left(\mathrm{h}_{\text {seep, exp }}\right)$ obtained with the developed tool for the same scenarios that have been chosen from Hall's experiments. $Q_{\exp }$ is also multiplied by $10^{-3}$. Table 2: Data from simulations.

\begin{tabular}{|c|c|c|c|}
\hline Test & $\mathbf{h}_{\text {well }}(\mathbf{m})$ & $\mathbf{Q}_{\exp }\left(\mathbf{m}^{\mathbf{3}} \mathbf{/ s}\right)$ & $\mathbf{h}_{\text {seep, exp }}(\mathbf{m})$ \\
\hline A-2 & 0.912 & 3.45 & 1.057 \\
\hline A-6 & 0.304 & 7.33 & 0.852 \\
\hline A-8 & 0.000 & 7.85 & 0.821 \\
\hline
\end{tabular}

\section{Comparison of results}

Table 3 presents the deviation between the results presented in Hall's paper and those calculated with the network method. The deviations are estimated with equation 1 for water flow and equation 2 for seepage surface:

$$
\begin{gathered}
\text { Deviation } Q=\left|\frac{Q_{\text {Dup }}-Q_{\text {exp }}}{Q_{\text {Dup }}}\right| * 100 \% \\
\text { Deviation } h_{\text {seep }}\left|\frac{h_{\text {seep }_{\text {Hall }}}-h_{\text {seep }} \text { exp }}{h_{\text {seep }}}\right| * 100 \%
\end{gathered}
$$

Table 3: Comparison of results.

\begin{tabular}{|c|c|c|c|c|c|c|c|c|}
\hline Test & $\begin{array}{c}\mathbf{h}_{\text {well }} \\
\mathbf{( m )}\end{array}$ & $\begin{array}{c}\mathbf{h}_{\text {seep, Hall }} \\
\mathbf{( m )}\end{array}$ & $\begin{array}{c}\mathbf{Q}_{\text {Hall }} \\
\left(\mathbf{m}^{\mathbf{3}} / \mathbf{s}\right)\end{array}$ & $\begin{array}{c}\mathbf{Q}_{\text {Dup }} \\
\left(\mathbf{m}^{\mathbf{3}} \mathbf{s} \mathbf{s}\right.\end{array}$ & $\begin{array}{c}\mathbf{Q}_{\mathbf{e x p}} \\
\left(\mathbf{m}^{\mathbf{3}} \mathbf{s} \mathbf{)}\right.\end{array}$ & $\begin{array}{c}\mathbf{h}_{\text {seep, exp }} \\
\mathbf{( m )}\end{array}$ & $\begin{array}{c}\text { Deviation } \\
\mathbf{Q} \mathbf{( \% )}\end{array}$ & $\begin{array}{c}\text { Deviation } \\
\mathbf{h}_{\text {seep }}(\mathbf{\%})\end{array}$ \\
\hline A-2 & 0.912 & 1.043 & 3.86 & 3.41 & 3.45 & 1.057 & 1.11 & 1.34 \\
\hline A-6 & 0.304 & 0.848 & 8.28 & 7.25 & 7.33 & 0.852 & 1.03 & 0.47 \\
\hline A-8 & 0.000 & 0.833 & 8.78 & 7.73 & 7.85 & 0.821 & 1.50 & 1.44 \\
\hline
\end{tabular}

According to the results in Table 3 the deviation between Hall's results and those obtained by the developed tool are never higher than $1.5 \%$, which can be considered as negligible. Therefore, this tool can be considered accurate enough to be employed for the estimation of the water flow outside an unconfined aquifer due to a pumping well and the seepage surface.

\section{Conclusion}

The network method has been the base to develop a numerical model for the calculation of water flow outside an unconfined aquifer due to a pumping well and the seepage surface in the well-ground contact. This last variable can only be obtained if vertical flow is considered.

In order to verify that the results of the tool are correct, Hall experimental results have been used to compare with those from the simulation. The deviations of the two results are so low (never higher than $1.5 \%$ ) that can be considered as negligible.

In this way, the developed tool can be considered accurate enough to estimate both water flow and seepage surface.

\section{Acknowledges}

We would like to thank the SéNeCa Foundation for the support given to this research and for the scholarship awarded to María Encarnación Martínez Moreno to carry out her doctoral thesis. 


\section{References}

[1] T. Distefano, and S. Kelly. "Are we in deep water? Water scarcity and its limits to economic growth". Ecological Economics, vol. 142, pp. 130-147. 2017.

[2] J. É. J. Dupuit, J. É. J. Études théoriques et pratiques sur le mouvement des eaux dans les canaux découverts et à travers les terrains perméables: avec des considérations relatives au régime des grandes eaux, au débouché à leur donner, et à la marche des alluvions dans les rivières à fond mobile. Dunod. 1863.

[3] H. E. Babbitt and D. H. Caldwell. The free surface around, and interference between, gravity wells. University of Illinois at Urbana Champaign, College of Engineering. Engineering Experiment Station. 1948.

[4] C. F. González-Fernández, "Applications of the network simulation method to transport processes," Network Simulation Method, Ed. J. Horno, Research Signpost, Trivandrum, India, 2002.

[5] G. García-Ros, I. Alhama, and M. Cánovas. "Powerful software to simulate soil consolidation problems with prefabricated vertical drains". Water, vol. 10, no. 3, pp. 242. 2018.

[6] J. Zueco, F. Alhama and C.F. González Fernández. "Inverse problem of estimating time-dependent heat transfer coefficient with the network simulation method". Communications in Numerical Methods in Engineering, vol. 21, no. 1, pp. 39-48. 2005.

[7] Ngspice. Open Source mixed mode, mixed level circuit simulator (based on Bekeley's Spice3f5). 2016 [Online]. Available: http://ngspice.sourceforge.net/

[8] H.P. Hall. "An investigation of steady flow toward a gravity well”. La Houille Blanche, vol. 1, pp. 8-35. 1955. 